\title{
Formação de classes de respostas, resistência à mudança e terapia comportamental infantil
}

\author{
Response-class formation, resistance to change, and child behavioral \\ therapy
}

Jaíde Aparecida Gomes Regra ${ }^{1}$

[1] Consultório particular, Brasil | Título abreviado: Classes de respostas e resistência à mudança | Endereço para correspondência: Jaíde Regra. Rua Piauí, 77, Apto.12. CEP: 01241-001. São Paulo, SP.|E-mail: jaideregra@hotmail.com

Resumo: Compreender o processo de formação de classes de respostas pode auxiliar na análise do comportamento complexo. A resistência à mudança dificulta o trabalho do terapeuta comportamental. Identificar variáveis que favorecem o desdobramento de classes de respostas é um desafio para o analista do comportamento. O objetivo do presente trabalho é identificar variáveis relevantes que dificultam a formação de nova classe de resposta e intervenções que alterem as classes de respostas pré-estabelecidas. Estudos recentes mostram dificuldades na aquisição de nova classe de resposta quando outra classe já tenha sido anteriormente estabelecida. É importante considerar tanto a aversividade dos estímulos presentes na formação da nova classe de resposta como a sobreposição do comportamento operante e respondente. A análise de amostras de interações entre terapeuta e criança mostra pequenas mudanças de respostas verbais. A intervenção pretendeu desdobrar uma classe de resposta em duas classes menores. Ao identificar novas classes de respostas e suas consequências, a criança pode alterar a classe de resposta anterior. Esta análise sugere que as alterações ocorridas nas classes de respostas resistentes possam ter a função de expor a criança a novas contingências.

Palavras-chave: classes de respostas, resistência à mudança, equivalência de estímulos, terapia comportamental infantil

Abstract: Understanding the process of response classes formation may help in the complex behavior analysis. The resistance to change hampers the behavioral therapist work.

Identify variables that help the response classes unfolding is a challenge for the behavior's analyst. The aim of this study is to identify relevant variables that increase difficulties to the new response class formation and interventions that modify the pre-established response classes. Recent studies show difficulties in acquiring new response classes when another class has been previously established. It is important to consider the aversive stimuli present in the new response class formation as well as the superposition of the operant and respondent behavior. The analysis of interactions samples between therapist and child shows small changes in the verbal responses. The intervention pretended to unfold a response class into two smaller classes. By identifying new classes of responses and their consequences, the child can change the previous response class. This analysis suggests that the changes occurred in the resistant response classes may have the function of exposing the child to new contingencies.

Keywords: response classes, resistance to change, stimulus equivalence, child behavioral therapy 
São muitos os problemas com os quais se depara o terapeuta comportamental infantil. Muitos fenômenos complexos estão diante de nós, terapeutas, e não dispomos de resultados de pesquisas que forneçam um suporte ao trabalho clínico. O que fazer? Muitas são as questões que se colocam. Como elaborar procedimentos a partir da análise do comportamento complexo? Como prevenir recaídas? O que é comportamento "resistente" à mudança? São os comportamentos que resistem à mudança ou a persistência dos comportamentos "disfuncionais" ocorre devido à dificuldade em identificar as variáveis relevantes? O cliente "não quer" mudar ou o seu comportamento está sendo mantido por variáveis não identificadas pelo terapeuta? Como alterar uma classe de respostas resistente à mudança?

Um exemplo do que ocorre na clínica pode ilustrar os tipos de eventos com os quais o terapeuta infantil deve lidar: "Ninguém gosta de mim", dito por uma criança de oito anos que fica isolada no recreio e não consegue brincar, mostra as dificuldades que surgem no ambiente terapêutico. Hipóteses são levantadas sobre a possível formação de classes de respostas nesse contexto.

Classe 1: "Peço para brincar com as crianças no recreio". / "Elas dizem não". / "Elas me xingam". / "Dão risada de mim". / "Chego perto e elas saem". / "Elas me batem".

Ensinar a criança a identificar a relação entre seu próprio comportamento e as consequências no ambiente pode favorecer o processo: "Se eu me comporto da maneira A e eles se afastam e, quando me comporto da maneira B, eles se aproximam", pode favorecer a seleção do comportamento pela consequência. Mas, se a criança está sob controle de uma regra - "Eles não brincam comigo porque sou negra" -, ela acredita que as consequências independem de seu comportamento. A dificuldade que se coloca é: como torná-la sensível às contingências?

A formação de conceito ocorre a partir de um conjunto de eventos no ambiente natural que leva a criança a estabelecer novas relações entre os estímulos, formando novas classes de respostas, provavelmente via equivalência de estímulos.

A maioria das perguntas colocadas não pode ser respondida no momento pela falta de pesquisas esclarecedoras. Muitos desses problemas são observados na análise do processo de formação das classes de equivalência. $\mathrm{O}$ fenômeno está diante dos terapeutas e pede uma intervenção imediata. Não encontrando respaldo na pesquisa clínica com procedimentos testados para alterá-lo, o terapeuta comportamental deve encontrar uma forma de lidar com o fenômeno. Uma das maneiras seria começar por uma busca na literatura em pesquisa básica.

Essa literatura dispõe de alguns trabalhos que discorrem sobre a formação de classes de equivalência, o que nos ajuda a compreender o processo de formação de conceitos, com destaque para trabalhos sobre a resistência à mudança nas classes de respostas. Pilgrim e Galizio (1990) apresentam trabalhos relevantes que vão ao encontro das nossas questões quando afirmam que, embora existam muitos estudos sobre o estabelecimento das relações de equivalência, pouco se sabe sobre como essas relações podem ser modificadas. Essa informação de quase duas décadas não nos consola ao notar que nem a pesquisa básica tem respostas para as questões prementes dos terapeutas comportamentais.

Após cinco anos, temos outra implicação bastante séria decorrente dos trabalhos de Pilgrim e Galizio (1995a, 1995b), relacionada ao fato de que classes formadas pelas relações de equivalência tendem a ser estáveis e resistentes a mudanças. Poucos estudos demonstraram a reversão das classes de equivalência, quando introduzidos controles metodológicos específicos (Garotti, Souza, de Rose, Molina, \& Gil, 2000; Smeets, Barnes-Holmes, Akppinar, \& Barnes-Holmes, 2003), atribuindo às dificuldades de reversão variáveis identificadas como: introdução prematura das provas (teste de equivalência), controle por dicas contextuais, uso de estímulo atípico (e.g., três dimensões), topografia da resposta, tipo de aparelho usado e mudança de reforçamento contínuo para intermitente.

Smeets, Barnes-Holmes, Akppinar e BarnesHolmes (2003) consideram que as descobertas em seus resultados sugerem que o desempenho dos participantes, para reverter ou não as classes de equivalência, estava sob controle de dicas contextuais. Em 1989, o controle contextual foi muito bem demonstrado por Bush, Sidman e de Rose. Os poucos resultados na literatura (Dube \& McIlvane, 1995; Garotti et al., 2000; Smeets et al., 2003) que reverteram classes de equivalência são animadores para terapeutas comportamentais como um início 
da investigação que poderá embasar o desenvolvimento da pesquisa em clínica. São trabalhos recentes que mostram as dificuldades metodológicas para obtenção de resultados tanto na pesquisa básica como na pesquisa aplicada.

Retomando um dos primeiros estudos sobre as dificuldades em reverter classes de equivalência, com um detalhamento do trabalho de Pilgrim e Galizio (1990) em estudos de laboratório, pode-se esclarecer o tipo de dificuldade encontrada. Após o teste de equivalência de estímulos demonstrando a emergência das novas relações, os participantes receberam treino posterior em que as relações originais A-C eram revertidas, ou seja, A1-B1, A2-B2, A1-C2, A2-C1. Este procedimento provocou alterações nas respostas de simetria de três dos quatro participantes, mas nenhum deles respondeu de acordo com as relações de transitividade, como seria esperado para as novas discriminações condicionais. O desempenho dos participantes no teste de equivalência não foi controlado pelas contingências de discriminação condicional modificadas que estavam em vigor, mesmo quando o desempenho nas provas de simetria estava sob controle das novas contingências.

Essas descobertas são consistentes com os resultados de Spradlin, Saunders e Saunders (1992), ao mostrar que o desempenho nos testes de equivalência de estímulos é menos resistente a mudanças quando os participantes são crianças e mais resistente a mudanças com participantes adultos (Pilgrim \& Galizio, 1995a, 1995b).

É uma boa notícia para os terapeutas comportamentais infantis que enfrentam as mesmas dificuldades dos terapeutas de adultos. Esses dados corroboram a experiência clínica que tem mostrado que crianças menores podem mudar as classes de respostas mais rapidamente, embora isto só ocorra em outros ambientes quando os pais seguem a orientação dada pelo terapeuta e também alteram suas classes de respostas. Ambas as variáveis parecem relevantes: o tempo de formação das classes de respostas da criança e a mudança nas classes de respostas dos pais.

É relevante destacar um trabalho sobre resistência na formação de novas relações de equivalência quando outra classe de respostas incompatível já havia sido instalada em ambiente natural. A im- portância desse estudo se deve ao fato de selecionar classes de respostas formadas no ambiente natural para serem submetidas a mudanças em situação de laboratório. Nele, Watt, Keenan, Barnes e Cairns (1991) utilizaram-se da situação social na Irlanda do Norte, onde a convivência entre grupos católicos e protestantes - com formação de identidades muito diferentes - provocava constantes conflitos. Os autores observaram a ocorrência de resistência na formação de novas relações de equivalência com "estímulos contaminados socialmente", em participantes adultos. Segundo Watt et al., as pessoas da Irlanda do Norte usam muitas informações para identificar e categorizar cada um dos grupos religiosos, como o nome dos indivíduos. Os nomes são arranjados conforme o grupo de nomes católicos e protestantes. O nome das pessoas pode identificálas como pertencentes a um ou outro grupo. No exemplo mencionado pelos autores, uma pessoa que viveu em uma comunidade onde o nome Sean está positivamente relacionado com o contexto católico, e católico está positivamente relacionado com terrorismo, então o princípio comportamental de equivalência de estímulo faz com que Sean e terrorismo sejam vistos como estímulos equivalentes. Com esta interpretação comportamental, os autores sugerem que respostas a estímulos podem depender de suas relações com outros "estímulos contaminados socialmente", e não só da história de reforçamento direto com o referido estímulo.

Nesse estudo de Watt et al. (1991), os participantes foram treinados a relacionar três nomes católicos a três sílabas sem sentido e, em seguida, relacionar as sílabas sem sentido a três símbolos protestantes. Foi usado um procedimento padrão de equivalência de estímulo. Na fase de teste, um novo nome protestante foi introduzido como um dos três estímulos de comparação. Os grupos de participantes foram organizados de acordo com a afiliação religiosa e a nacionalidade. Em seguida, três novos nomes - católicos, protestantes e neutros - foram usados para um teste de generalização. Quando nomes católicos e símbolos protestantes foram empregados no procedimento de equivalência, ocorreu "falha" no desempenho dos participantes da Irlanda do Norte para emergir as relações de equivalência previstas pelo procedimento. Embora o procedimento experimental previsse a formação 
de relações de equivalência ligando nomes católicos a símbolos protestantes, muitos participantes da Irlanda do Norte escolhiam nomes protestantes não treinados na presença desses símbolos.

Uma possível explicação dada sobre esse efeito se apoia na suposição de que relações de equivalência entre símbolos protestantes e nomes protestantes, estabelecidas socialmente fora do laboratório e anteriores ao estudo experimental, impediram a formação no laboratório de relações de equivalência contraditória entre nomes católicos e símbolos protestantes. Essa hipótese recebe apoio nos estudos de Saunders, Saunders, Kirby e Spradlin (1988), Pilgrim e Galizio (1990) e Moxon, Keenan e Hine (1993), ao mostrar a dificuldade em "quebrar" relações de equivalência anteriormente estabelecidas em adultos.

Outra possível explicação para os resultados de Watt et al. (1991) poderia estar relacionada à dificuldade na formação da classe, não só porque já havia sido formada uma classe incompatível préexperimentalmente, mas também devido ao fato de a formação da classe na situação experimental relacionar símbolos associados com estímulos aversivos na história de vida do participante. Temos de ter olhos para a sobreposição operante-respondente na formação de classes de respostas equivalentes. Algumas hipóteses a considerar:

Hipótese 1 - Regra (2003), usando procedimento de equivalência de estímulo, ao emparelhar o nome de crianças com a palavra esperta em um grupo, enquanto no outro grupo as crianças tinham seu nome emparelhado com lenta, obteve resultados que mostraram que as crianças emitiam respostas que eram seguidas por "está certo", mesmo que para isso tivessem de emparelhar seu nome à palavra lenta. Esses resultados aconteceram com maior frequência entre os participantes que tiveram histórias de reforçamento com a palavra esperta, no ambiente natural. Supôs-se que a resposta era controlada por "acertar", o que torna este procedimento artificial e distante do ambiente natural. Os resultados sugerem que a criança estabeleceu outra relação: "Se acerto emparelhando meu nome com lenta, sou esperta". Se isto ocorreu, esta condição paradoxal não estava prevista nos controles do procedimento e, portanto, não avaliou o autoconceito relacionado a ser nomeada como lenta no ambiente natural, como se pretendia.
Hipótese 2 - Se as explicações estiverem fundamentadas na superposição operante-respondente, seria esperado que as crianças que tivessem seu nome ligado à palavra lenta teriam mais dificuldades na formação de classes do que aquelas que tivessem seu nome ligado à palavra esperta. É relevante buscar variáveis diferentes sob as quais cada grupo estaria sob controle. A análise desses resultados sugere ainda a existência de variáveis que interagem nestas condições. Duas delas foram destacadas: "acertar" e "aversividade" da palavra lenta. As crianças que apresentavam história de sucesso escolar, com muitos eventos relacionados com acertos, pareciam ter suas escolhas sob controle do "acertar", não sendo afetadas pela "aversividade" da palavra lenta. As crianças que tinham história de fracasso escolar, com muitos eventos relacionados a "errar", pareciam ter suas escolhas controladas pela "aversividade" da palavra lenta (Regra, 2003).

Alguns estudos (Nevin, 1984; Nevin, Tota, Torquato \& Shull, 1990) sugerem que a manutenção da taxa de resposta depende de procedimentos operantes das contingências reforço-resposta, enquanto a resistência à mudança depende do condicionamento respondente (Pavloviano) com as relações estímulo-reforço. A força da relação estímulo-reforço acontece quando mais reforçadores ocorrem na presença dos estímulos componentes.

$\mathrm{Na}$ prática clínica, é importante considerar a sobreposição operante-respondente e englobar na análise a resistência à mudança, questionando as relações com a aversividade dos estímulos.

Skinner $(1935,1937)$ mostrou que um estímulo anterior era desnecessário para a emissão de um comportamento operante, mas se sabe que em muitas situações um estímulo é a ocasião para a emissão da resposta devido à sua correlação temporal com o reforçamento. Por outro lado, no caso do comportamento respondente, a apresentação de um estímulo é necessária para a eliciação de uma resposta. $\mathrm{Na}$ tradição de pesquisa, os paradigmas operante e respondente deram origem a um campo de investigação em que os comportamentos operantes e os comportamentos respondentes eram estudados de forma separada. Isto pode ter ocorrido pela dificuldade em encontrar uma metodologia adequada que abarcasse os dois paradigmas. 
Porém, tratam-se de processos separados?

Existem amplas evidências de que classes respondentes e operantes não ocorrem separadas (Rehfeldt \& Hayes, 1998), como as pesquisas de supressão condicionada (e.g., Estes \& Skinner, 1941) nas quais um estímulo incondicional aversivo é usado como sinal que antecede a resposta mantida por reforçamento positivo, podendo reduzi-la a taxas abaixo de sua linha de base.

Rehfeldt e Hayes (1998) argumentam que condicionamento operante e condicionamento respondente são ambos formas de controle de estímulo, devendo ser questionada a utilidade dessa distinção. Os autores ressaltam a importância de diferenciar entre estímulo discriminativo operante e estímulo condicionado (CS) respondente, que estão ambos correlacionados temporalmente com o estímulo incondicionado (US). Se é de conhecimento que o comportamento ocorre após a apresentação do US no paradigma respondente, é concebível que o CS também adquira funções discriminativas.

Considerando as dificuldades em reverter classes de equivalência, Garotti et al. (2000) levantam, entre outras, uma explicação para as diferenças nos resultados entre seus estudos - os quais não encontraram a referida resistência na mudança de classe - e os de Pilgrim e Galizio (1995a, 1995b). A revisão da linha de base que precedia cada teste no estudo de Garotti et al. (2000) pode ter funcionado como dicas contextuais, definindo o número de membros de classe após a linha de base reversa.

Os estudos que procuram analisar as variáveis relevantes para formação e reorganização de classes de respostas com resistência a mudanças, em laboratório, sugerem que:

(1) A história de reforçamento seja construída durante o estudo de laboratório, para que se possa trabalhar com uma história sob controle de variáveis conhecidas ao invés de uma história suposta. Fazendo algumas considerações sobre a clínica, dispomos da possibilidade de levantar dados para identificar uma história de reforçamento suposta. Ao procurar alterar parte da história de reforçamento, continuamos com uma história suposta.

(2) Seja considerada como variável relevante o tempo que a classe é formada e está sendo mantida, ou seja, a duração da história de reforçamento. Na clínica, esta variável também é relevante para o levantamento dos dados que irão favorecer a análise de comportamento.

(3) Possam ser analisadas todas as variáveis passíveis de interferir na formação da classe. No contexto clínico, temos de elaborar formas de intervenção que possam "quebrar" classes disfuncionais e favorecer a construção de novas classes de respostas funcionais e incompatíveis com as classes disfuncionais.

(4) Se busquem as variáveis envolvidas na reorganização da classe (Garotti et al., 2000). Na clínica, uma classe ampla pode ser subdividida em duas classes menores. Exemplo: a classe "Todos os homens são falsos" poderia ser dividida em duas classes - "Alguns homens são falsos" e "Alguns homens são verdadeiros". Um procedimento de discriminação poderia favorecer o processo, por meio de tarefas em que a criança iria observar no ambiente natural. A tarefa consistiria em retirar pistas dos eventos ambientais para que a criança discutisse com o terapeuta e aprendesse a reorganizar as classes. Nessa reorganização, ela aprenderia a reclassificar os comportamentos de acordo com as pistas observadas e conforme as consequências que se seguem a cada membro da classe. Por exemplo: a criança colocaria na classe nomeada como falso os comportamentos observados que tivessem pistas sobre falsidade e, em outra classe nomeada como verdadeiro, ela colocaria outros comportamentos em acordo com as pistas sobre verdadeiro (Regra, 2001). Ao formar nova classe cujos membros englobam os comportamentos verdadeiros, ocorre a mudança do conceito “Todos os homens são falsos" (e eu os trato mal) para o novo conceito formado "Alguns homens são verdadeiros" (e eu posso tratá-los bem). A formação da nova classe altera a emissão de alguns comportamentos e a criança ficará sob controle das novas contingências que se encarregarão de completar o processo.

(5) Se atente para as variáveis topográficas que podem afetar os resultados dos testes de equivalência.

(6) Seja considerada na análise dos dados escolhas controladas pelo estímulo contextual (Bush et al., 1989). 
(7) Seja levado em conta que equivalência de estímulos é um processo comportamental básico e que os fracassos nos testes de equivalência podem ser artefatos, devidos a medidas inapropriadas da topografia de controle de estímulos (Wilkinson, Souza \& McIlvane, 2000).

(8) Se observe um número maior que dois, no estímulo comparação, nos procedimentos de equivalência de estímulo. Sidman (2000) mostra em sua análise que o uso de apenas dois estímulos de comparação é perigoso, pois não podemos afirmar se a comparação foi o que o participante escolheu ou o que ele rejeitou (Regra, 2003).

$\mathrm{Na}$ clínica e no ambiente natural, são feitas interpretações sobre o processo de formação de classes. A utilização do estudo descritivo para selecionar variáveis relevantes e as contingências do ambiente natural e terapêutico responsáveis pelo fenômeno a ser estudado parece ser uma proposta interessante para os estudos de laboratório. Seu emprego facilita o estudo das variáveis do ambiente natural, removendo-se as variáveis artificiais criadas em laboratório em alguns estudos experimentais. Isto poderia gerar maior intercâmbio entre estudos de laboratório, pesquisa aplicada e trabalho clínico.

A resistência à mudança pode depender, entre outros fatores, da falta de dados sobre maneiras de alterar classes de respostas e da ausência de procedimentos que englobem intervenções na sobreposição operante-respondente. É difícil elaborar intervenções que alterem classes de respostas complexas, provoquem a mudança em conceitos e regras e tornem a criança sensível às contingências.

Alguns exemplos podem tornar mais claro como efetuar hipóteses na clínica sobre as variáveis que mantêm uma classe de respostas complexa. Classe de respostas são agrupamentos hipotéticos de comportamentos em que todos compartilham da mesma função, mesmo quando a topografia dos comportamentos específicos em uma classe particular é muito diferente (Sturmey, 1996). Esta definição é importante ao trabalho clínico e auxilia o terapeuta na análise de classes de estímulos e respostas.

Ao considerar a classe de comportamentos $g a$ nhar um jogo com humildade, temos uma ação ganhar - cujo nome indica a classe de respostas que tem alguns membros observáveis, outros membros que não foram identificados e ainda outros membros que poderão fazer parte da classe, se ocorrer transferência de funções de estímulos.

.../.../não ser exibido /eu ganhei porque treinei e você pode treinar também/você fez boas jogadas /elogiar o adversário/.../...

Comportamentos da classe de resposta perder com humildade e quem perde é o grande vencedor e a sobreposição operante-respondente.

Exemplo: terapeuta $(\mathrm{T})$ e criança $(\mathrm{C})$ jogando DiscoBoll, jogo com dois goleiros que se joga fazendo gol a gol.

(T) [Fez um gol e fica em silêncio]

(C) [A criança continua jogando em silêncio]

(T) Você enfrentou bem! Foi corajoso! [corajoso parece uma palavra forte que elicia emoções confortáveis pareadas com o perder e desafia a criança a enfrentar o perder e ser corajosa]

(C) [Fez um gol]

(T) Que golaço! Vamos rever a jogada [faz tirateima]

(T) [Faz segundo gol]

(C) Esse gol foi bonito! [a criança imita o modelo do terapeuta de elogiar o adversário ao invés de jogar o tabuleiro como fazia antes; a emoção confortável pareada com ser corajoso parece ter favorecido a formação da nova classe de comportamentos]

(T) E você está sendo vencedor! Ah! Não quero mais fazer gol porque se eu perder serei a vencedora (risos).

\section{Exemplo de comportamentos muito resistentes à mudança}

Comportamentos que envolvem alteração de classes de estímulos, formadas possivelmente por relações de equivalência de estímulo e que exigem uma reorganização nos membros dessas classes que podem levar à alteração de conceitos e à mudança de regras.

Amostras de sessão de um garoto de onze anos, Paulo (P), com inabilidade social e inflexibilidade (classes de respostas que não se modificam frente a uma interação social comum ao ambiente natural: dificuldade em ceder e aceitar o argumento do outro).

A criança traz para a sessão de terapia um relato verbal composto por sequências comporta- 
mentais que descrevem emoções de raiva voltada para uma criança que mora em seu prédio. Mara (M) é uma criança que brinca de escolinha com a irmã de Paulo, a Júlia (J). Paulo diz que somente ele pode ser o professor da irmã. O terapeuta tem a informação de que (P) não mantém relacionamentos interpessoais com outras crianças, sempre ocorrendo brigas e agressões físicas por querer que os outros façam tudo como ele quer, tanto na escola como no seu prédio.

\section{Descrição resumida do relato verbal de duas sessões terapêuticas com $(P)$}

(P) Júlia gosta de descer. Me dá um ciúmes porque, em casa, eu sou o professor dela. Lá embaixo, no prédio, a Mara é a professora dela. Eu quero que seja só eu o professor dela. Você arranja um jeito de só eu ser o professor dela? [P. faz um desenho contendo duas carinhas e a interação com o terapeuta começa na terceira pessoa, referindo-se ao desenho, embora use seu próprio nome].

\section{Interação entre terapeuta e criança}

(T) Situação imaginativa: se você estivesse com dois amigos e visse a Mara dando aula para a Júlia...

(P) Eu ia mandar a Mara parar de dar aula, mas eu não ia dar aula pra Júlia. Ia mandar a Júlia parar a aula e brincar com a gente. Mas a Mara ia ficar sozinha. Deixa. Ela é chata mesmo. Fica roubando minha irmã de mim.

(T) Se você quiser impedir tudo que sua irmã faz com outra pessoa pode ser muito difícil.

(P) Ela pode brincar com todo mundo, até com a Claudia que eu detesto, mas uma coisa eu não permito: que ela tenha aula com a Mara. Só eu sou o professor dela.

Tarefa do terapeuta: reorganizar ou separar a classe de comportamentos não permito em duas classes menores:

(1) Coisas que acho que tenho o direito de não permitir.

(2) Coisas que acho que não tenho o direito de impedir.

(T) Propõe situação imaginativa 1: Imagine que você está vendo a Mara dando aula pra Júlia.

(P) Eu arranco a cabeça dela e dou muitas bolachas. Conversei com a Júlia e ela me prometeu que nunca mais vai ter aula com a Mara, mas se por acaso eu encontrar a Júlia tendo aula com a Mara eu quebro a cara da Mara.

(T) Regra ${ }^{\circ}$ 1: Eu posso sentir raiva, mas nunca posso expressar a raiva machucando alguém.

(P) Se a pessoa irrita você, é nela que vai soltar a raiva.

(T) Se a pessoa irrita, tenho que usar a inteligência para falar com ela e achar um jeito de ela parar de me irritar.

(P) Mas é muito chato. Falo com ela e ela diz: "Eu não vou parar de fazer isso".

(T) Vamos imaginar a situação 2: Você desce e vê a Mara dando aula para Júlia.

(P) Ããã.

(T) Mas o Paulo já tem um plano: Vamos fazer o plano A do Paulo...

(P) Compro uma luva de box e mato ela.

(T) O plano inteligente: Paulo telefona para o Carlos [amigo do prédio].

(P) E aí a gente se junta e mata ela.

(T) Telefona para o Carlos e Paulo dá aula para o Carlos.

(P) Nem pensar. Eu que vou dar aula pra Júlia. Eu não vou deixar a Mara dar aula pra Júlia. Não deixo, não deixo. Nem que pra isso eu tenha que bater nela.

(T) Regra $n^{\circ} 2$ : Ninguém pode mandar no outro.

(P) Eu posso.

(T) Por que você pode?

(P) Porque na minha irmã quem manda nela sou eu, não elas.

(T) Mas elas não mandam. Elas fazem um convite gostoso e a Júlia aceita. Se elas mandarem e obrigarem a Júlia a brincar com elas, a Júlia não vai gostar e nem vai querer. E se você também fizer um convite gostoso?

(P) Mas elas são muito chatas. Outro dia estava chato lá embaixo e eu queria que minha irmã e minha prima subissem e a Mara se metendo disse: "Não percebeu que elas não querem subir?"

(T) Estava chato para você?

(P) Não. Estava chato mesmo pra Júlia também.

(T) Mas a gente não pode mandar no outro. Você tem que aprender a usar truques para fazer o outro querer.

(P) Eu quero dar aula pra minha irmã e só eu. 
Não tem jeito. Ela vai ter que querer.

(T) Regra $n^{\circ}$ 3: A gente tem que aprender a aceitar quando o outro não quer.

(P) Mas aí não. A Júlia vai ter que ter aula comigo.

(T) Se você aprender a deixar o outro escolher, vai ser mais feliz.

(P) Eu só vou ser feliz se eu der aula pra Júlia.

(T) Você não quer aprender isso por quê? Você sente muito ciúmes, não é?

(P) É.

(T) Então vamos entender o que é o ciúmes. O que você acha que é o ciúmes?

(P) É quando eu quero que ela faça alguma coisa e ela está fazendo outra e ela fica com outra pessoa ao invés de ficar comigo.

(T) Que beleza de idéia! Vamos fazer a situação imaginativa 3: Paulo está sozinho. Queria ficar com a Júlia e a Júlia fica com outra pessoa e não quer ficar com Paulo. E Paulo fica sozinho.

(P) Paulo enche Júlia de bolacha até ela concordar em brincar comigo.

[Identificação de alguns membros da classe de respostas tudo deve ser feito do jeito que eu quero. Entre os possíveis membros da classe, estão: "Júlia vai ter que ter aula comigo"; "Fiz a Júlia prometer nunca mais ter aula com a Mara"; "Vou mandar a Mara parar de dar aula"; "Eu não permito que Júlia tenha aula com Mara"; "Se não fizer como eu disse, arranco a cabeça dela"; "Eu posso mandar"; "Ela vai ter que querer"; "Encho de bolacha até ela concordar".]

(T) E Paulo consegue que Júlia brinque com ele por causa do medo das bolachas e não porque ela está feliz e gostando de brincar na marra. Se Paulo faz um convite legal e Júlia aceita, Júlia brinca com Paulo porque é gostoso e fica feliz. O truque é fazer o outro querer e gostar de ficar junto [T. descreve a consequência para os membros da classe mencionada e as alternativas de comportamento com suas consequências].

(P) Ããã. Se Paulo fizer um convite legal e Júlia não aceitar, Paulo vai ficar morrendo de raiva e vai explodir [P. descreve a consequência para si mesmo se Júlia não fizer do jeito que ele quer].

(T) Paulo só vai explodir se estiver sozinho e não tiver amigos. O grande truque que as pessoas aprendem para não explodir: se essa pessoa não me quer agora, eu tenho muitos outros amigos. Mas para usar esse truque, primeiro você precisa arrumar mais amigos que você goste e daí pode escolher só os que quiserem você. Só dá para ser feliz quando alguém fica comigo porque se sente bem e escolheu isso e não quando fica na marra. Então nossa tarefa é:

(1) Investir em novos amigos (dar aula para eles e fazer brincadeiras muito legais).

(2) Quando quiser dar aula para a Júlia e ela aceitar, dar aula de um modo gostoso.

(3) Se ela quiser ter aula com a Mara, ela pode escolher.

(P) Ela vai ter que aceitar senão vai levar bolacha.

(T) Paulo só vai ser feliz tendo alguém do lado que fica com ele porque quer; que é livre para ficar com ele.

(P) Paulo ficará feliz se Júlia não tiver aula com a Mara.

(T) Mas para o Paulo conseguir isso demora um pouco, porque vai ter que aprender muitos truques: (1) investir no Carlos e em novos amigos; (2) se Júlia não quiser aula, mostrar para Júlia que você tem o Carlos (tem alternativas); (3) a Júlia também pode ficar com ciúmes e querer ter aula com você [os "truques" são usados como operações estabelecedoras, que amplificam os reforçadores e aumentam a probabilidade da criança "querer fazer" o que está sendo proposto por T.]

(P) Mas até lá a Mara ensinará coisas à Júlia [começa a reduzir a "resistência" e aceita argumentar com a variabilidade de resposta. $\mathrm{Na}$ "inflexibilidade" inicial, aparecia a mesma resposta verbal. Agora variou a resposta].

(T) Até lá Paulo também ensinará coisas à Júlia e poderá ficar feliz quando Júlia ficar com ele sem ser na marra.

(P) Mas a Júlia vai aprender um monte de coisas com a Mara.

(T) Mas toda felicidade tem um preço.

(P) Mas eu não aceito esse preço.

(T) Então você escolhe: ou paga esse preço e fica feliz, ou não paga esse preço e pode ficar infeliz conseguindo a Júlia na marra e que ela fique com você por medo, certo? [o objetivo do terapeuta é 
desdobrar a classe as coisas devem ser do jeito que eu quero em duas classes menores: algumas coisas podem ser do jeito que eu quero e podem demorar mais tempo e outras coisas não podem ser do jeito que eu quero. A hipótese de T. de "quebrar" uma classe em duas outras classes menores seria possível pela discriminação dos contextos seguidos de suas consequências].

(P) Ah! Mas não tem outro jeito?

(T) Eu não vejo nenhum. Você conhece outro jeito?

(P) Se ela parar de ter aula com a Mara e ficar comigo sem ser na marra [observa-se neste relato verbal uma alteração na classe as coisas devem ser do jeito que eu quero, mesmo que seja na marra para as coisas devem ser do jeito que eu quero sem ser na marra].

(T) Esse é um jeito que depende dela e não de você. Para ela "querer" ter aula com você, ela terá que gostar muito quando ficar com você. E pra ela gostar muito, você terá que fazer coisas muito agradáveis para ela. Aí vai depender de você. E mesmo gostando muito, ela pode querer variar: um dia brinca com você e outro dia brinca com a Mara. E você, um dia brinca com ela e no outro dia brinca com o Carlos. Podemos começar com três tarefas para a semana que devem ser repetidas algumas vezes:

(1) Brincar com Carlos e outros amigos.

(2) Convidar Júlia e criar uma situação muito agradável com ela.

(3) Observar se ela aceita seu convite.

[P. termina a sessão combinando as três tarefas e volta na sessão seguinte dizendo que a "Júlia é uma escrava de Paulo"].

(T) A Júlia é uma escrava do Paulo. Analise isso que você falou.

(P) Eu sou o chefe e sou o bruxo-chefe e mando nela [em sessões anteriores, P. relatou que tem fantasias acordado, em casa, sobre ser um bruxochefe].

(T) Por que você quer ser o chefe?

(P) Porque é legal e eu sou bruxo.

(T) E por que é legal?

(P) Porque você manda nos outros e é muito legal.

(T) É legal pra quem? [T. procura desenvolver na criança a percepção do outro, imaginando que uma interação social deve ser legal para ambas as pessoas que interagem].

(P) Pra mim.

(T) E para os outros?

(P) Nem um pouco.

(T) E o que você imagina que eles pensam de você?

(P) Que eu sou um chato [pela primeira vez, aparece um início de autocrítica, ou seja, a criança avaliando o seu próprio comportamento].

(T) E por que é legal mandar e ser o chefe, se os outros acham que você é chato? [parece que confrontar-se com perguntas para a identificação do autoconceito, do que o outro pensa e sente e das consequências que se seguem a cada comportamento, favorece a formação de uma nova classe de comportamentos "funcionais" para o desenvolvimento de habilidades sociais].

(P) Porque é muito legal que o chefe tem bastante dinheiro e consegue tudo que ele quer.

(T) E o que ele quer?

(P) Ser rico e ter bastante ouro.

(T) Para que?

(P) Para ter tudo que quiser.

(T) Ele quer ser rico para ter tudo o que quiser. Vamos fazer uma lista do que ele quer.

(P) Castelo, coleção de carros importados, roupas caríssimas e chiques, ter todo mundo ajoelhado pra você e te respeitando, criados limpando a casa inteira, pratos de comida excelentes, casa de campo, ouro pra caramba, dinheiro pra ter excelente saúde e ser atendido em hospitais ótimos e escolas excelentes, emprego onde todos gostam de você. $\mathrm{E}$ com todo esse dinheiro quem sabe você pode ser o prefeito e que distribua melhor o dinheiro da cidade para os pobres. E para ter quadros de pintores famosos como Tarsila do Amaral e Picasso que é meu favorito, e para quem sabe ser conhecido no país ou mundo inteiro como o milionário bom e honesto porque divide seu dinheiro.

(T) Por que ter todo mundo ajoelhado e te respeitando e todos gostando de você?

(P) Ajoelhando, não porque eu estou mandando mas sim porque gostam tanto dessa pessoa que a tratam como um rei [observa-se uma mudança na classe de comportamentos as coisas devem ser do jeito que eu quero, mesmo que seja na marra para a 
nova classe verbal eles se ajoelham não porque estou mandando, mas porque gostam muito da pessoa. É uma mudança observável apenas no relato verbal. Não foi observado nesta fase uma mudança nos membros da classe correspondente ao "fazer"].

(T) Você está me dizendo que gostaria de ser muito amado e a imagem das pessoas ajoelhadas aos seus pés é uma imagem que você faz do amor?

(P) É.

(T) Agora eu queria que você me desse uma outra imagem do amor.

(P) Você não gostou dessa?

(T) Não é isso. É que é sempre bom pensarmos em várias imagens porque aí a gente pode variar.

(P) Tratar bem as pessoas e dar dinheiro a elas sem pedir nada em troca.

(T) Você já me fez duas imagens interessantes. Você conseguiria fazer mais uma imagem do amor?

(P) Ajudar as pessoas pobres dando dinheiro e comida aos que precisam.

\section{Conclusão}

Os terapeutas comportamentais em geral e os terapeutas comportamentais infantis se deparam com muitas dificuldades para alterar classes de comportamentos complexos. A literatura da pesquisa básica descreve alguns trabalhos que demonstram a resistência para alterar classes de equivalência, tanto as formadas em laboratório (Moxon et al., 1993; Pilgrim \& Galizio, 1990; Saunders et al., 1988) como as supostamente formadas em fase pré-experimental (Watt et al., 1991).

Trabalhos como os de Garotti et al. (2000) demonstram como a resistência à mudança para alterar classes de equivalência, nos trabalhos anteriores, se deveu a problemas metodológicos relacionados ao controle de variáveis. As pesquisas de Spradlin et al. (1992) falam sobre maior facilidade na mudança das classes de equivalência em crianças do que em adultos. A experiência clínica na terapia comportamental infantil corrobora esses resultados, observando maior facilidade de mudança em crianças menores, em ambiente natural.

Há poucos resultados obtidos na pesquisa bási$\mathrm{ca}$, o que indica a necessidade de desenvolvimento de um corpo de conhecimentos relacionado à área. O terapeuta comportamental levanta hipóteses a partir da literatura disponível e dos dados coletados com o cliente, faz análise funcional dos comportamentos e elabora suas intervenções procurando identificar variáveis que favorecem a resistência a mudanças. Uma das dificuldades descritas na mudança de classe pode estar relacionada à sobreposição operante-respondente, que na maior parte das pesquisas tem sido deixada de lado.

A análise da interação entre terapeuta e criança procurou mostrar formas de intervenção que podem favorecer a alteração e/ou reorganização das classes de comportamento complexo. A interação do terapeuta ora neutra e sem crítica para relatos "disfuncionais", ora oferecendo aprovação para relatos "funcionais", pode ter selecionado as respostas verbais da criança consequenciadas positivamente. Essas consequências positivas ligadas ao contexto positivo podem ter favorecido a interação operanterespondente tão importante para a reorganização dos membros das classes de respostas selecionada na sessão terapêutica.

A aquisição de uma nova classe de respostas ou o desdobramento de uma classe em duas classes menores pode favorecer a exposição a novos contextos e suas consequências. Através dessa análise foi possível observar pequenas mudanças nas respostas verbais da criança ao desdobrar uma classe em duas ou mais classes menores.

Ao identificar novas classes de respostas e suas consequências, a criança pode alterar a classe de resposta anterior. A análise da interação entre terapeuta e criança sugere que as alterações ocorridas nas classes de respostas resistentes à mudança possam ter a função de alterar a motivação (operações estabelecedoras) e levar a criança a se expor às novas contingências que se encarregarão de completar o processo de aquisição e manutenção da nova classe de resposta. A análise do comportamento sobre a interação entre terapeuta e cliente, nas sessões de terapia comportamental, fornece pistas sobre fenômenos e variáveis relevantes a serem estudados.

\section{Referências}

Bush, K. M., Sidman, M., \& de Rose, T. (1989). Contextual control of emergent equivalence. Journal of the Experimental Analysis of Behavior, 51, 29-45.

Dube, W. V., \& McIlvane, W. J. (1995). Stimulus- 
reinforcer relations and emergent matching to sample. The Psychological Record, 45, 591-612.

Estes, W. K., \& Skinner, B. F. (1941). Some quantitative properties of anxiety. Journal of Experimental Psychology, 29, 390-400.

Garotti, M., Souza, D. G., de Rose, J. C., Molina, R. C., \& Gil, M. S. A. (2000). Reorganization of equivalence classes after reversal of baseline relations. The Psychological Record, 50, 35-48.

Moxon, P. D., Keenan, M.; Hine, L. (1993). Genderhole stereotyping and stimulus equivalence. The Psychological Record, 43, 381-394.

Nevin, J. A. (1984). Quantitative analysis. Journal of the Experimental Analysis of Behavior, 42, 421434.

Nevin, J. A., Tota, M. E., Torquato, R. D., \& Shull, R. L. (1990). Alternative reinforcement increases resistance to change: Pavlovian or operant contingencies? Journal of the Experimental Analysis of Behavior, 53, 359-379.

Pilgrim, C., \& Galizio, M. (1990). Relations between baseline contigencies and equivalence probe performances. Journal of the Experimental Analysis of Behavior, 54, 213-224.

Pilgrim, C., \& Galizio, M. (1995a). Reversal of baseline relations and stimulus equivalence: I. Adults. Journal of the Experimental Analysis of Behavior, 63, 225-238.

Pilgrim, C., \& Galizio, M. (1995b). Reversal of baseline relations and stimulus equivalence: II. Children. Journal of the Experimental Analysis of Behavior, 63, 239-254.

Regra, J. A. G. (2001). A integração de atividades múltiplas durante atendimento infantil, numa análise funcional do comportamento. Em H. J. Guilhardi, M. B. B. P. Madi, P. P. Queiroz \& M. C. Scoz (Orgs.), Sobre comportamento e cognição: Vol. 8. Expondo a variabilidade (pp. 386397). Santo André, SP: ESETec.

Regra, J. A. G. (2003). Exercício de interpretação das relações de equivalência em situação clínica e experimental (Tese de doutorado não publicada). Instituto de Psicologia, Universidade de São Paulo, São Paulo.

Rehfeldt, R. A., \& Hayes, L. J. (1998). The operantrespondent distinction revisited: Toward an understanding of stimulus equivalence. The Psychological Record, 48, 187-210.
Saunders, R. R., Saunders, K. J., Kirby, K. C., \& Spradlin, J. E. (1988). The merger and development of equivalence classes by unreinforced conditional selection of comparison stimuli. Journal of the Experimental Analysis of Behavior, $50,145-162$.

Sidman, M. (2000). Equivalence relations and the reinforcement contingency. Journal of the Experimental Analysis of Behavior, 58, 173182.

Skinner, B. F. (1935). Two types of condicioned reflex and a pseudo-type. The Journal of General Psychology, 12, 66-77.

Skinner, B. F. (1937). Two types of conditioned reflex: A reply to Konorski and Miller. The Journal of General Psychology, 16, 272-279.

Smeets, P. M., Barnes-Holmes, Y., Akpinar, D., \& Barnes-Holmes, D. (2003). Reversal of equivalence relations. The Psychological Record, 53, 91-119.

Spradlin, J. E., Saunders, K. J., \& Saunders, R. R. (1992). The stability of equivalence classes. Em S. C. Hayes \& L. J. Hayes (Orgs.), Understanding verbal relations (pp. 29-43). Reno, NV: Context Press.

Sturmey, P. (1996). Functional analysis in clinical psychology. New York, NY: John Wiley \& Sons.

Watt, A., Keenan, M., Barnes, D., \& Cairns, E. (1991). Social categorization and stimulus equivalence. The Psychological Record, 41, 3350.

Wilkinson, K. M., Souza, D. G., McIlvane, W. J. (2000). As origens da exclusão. Temas em Psicologia, 8, 195-203.

\section{Informações do artigo}

\section{História do artigo}

data de submissão em: 01/09/2009

primeira decisão editorial em: 23/09/2009

aceito para publicação em: 04/10/2010 